\title{
Life cycle assessment - introduction and overview
}

The concept of environmental life cycle assessment (LCA) was developed from the idea of comprehensive environmental assessments of products, which was conceived in Europe and in the USA in the late 1960s and early 1970s [1]. Originally, LCA was used as a tool by environmental consultants. Eventually, it became clear that different LCAs carried through by different consultants resulted in different and sometimes conflicting conclusions [2,3]. The large differences in the LCA results could be explained, in part, by different methodological choices [4].

Many initiatives were taken to harmonise LCA methodology. These efforts resulted in methodological guidelines, most of which were valid for a specific geographical area $[5,6]$, a particular category of products [7-9], or a particular application of LCA [10-12]. General methodological guidelines were, in some cases, developed on the basis of consensus within a limited group $[13,14]$. A recent example is the "Handbook on Life Cycle Assessment", edited by Jeroen B. Guinée. A review of this handbook is included at the end of this issue of Journal of Cleaner Production. Another review also presented in this issue is that of the recent textbook "The Hitch Hiker's Guide to LCA" by Henrikke Baumann and Anne-Marie Tillman, which gives more of an orientation of the existing guidelines.

The various guidelines include different and often conflicting methodological recommendations. An effort to reach consensus on a broad, international level was initiated within the Society of Environmental Toxicology and Chemistry (SETAC) in 1990 [15]. The harmonisation process soon resulted in the so-called SETAC Code of Practice [16]. This document describes a procedural framework for LCA. It also includes some methodological recommendations. Since the Code of Practice was published, different international working groups within SETAC have been addressing different parts of LCA methodology. A summary of all recent SETAC reports on LCA is included later in this special issue.

In addition, a standardization process started within the framework of the International Organization for Standardization (ISO). The international standards that were developed and accepted in the late 1990s present recommendations or requirements for several methodological issues that were not covered in the SETAC Code of Practice [17-20]; however, many methodological problems remain unsolved in the ISO documents.

The obstacles encountered in the harmonisation and standardization of LCA methodology spurred the interest of the academic world. Development of LCA methodology and environmental research based on LCA methodology became widespread academic topics. A large number of papers on LCA have been published in Journal of Cleaner Production. The first special issue on LCA, No 3-4 in Volume 1, was printed as early as 1993. A journal specifically dedicated to LCA research (The International Journal of Life Cycle Assessment) was started in 1996. In addition, many scientific papers on LCA have been published in other journals dedicated to environmental science, such as Environmental Science and Technology and Resources, Conservation and Recycling, and in journals dedicated to specific sectors in society or specific types of products.

The volume of LCA research has grown rapidly since the beginning of the 1990s. Our first special issue on LCA included contributions from most of the important LCA researchers at that time. Such a comprehensive presentation of the research cannot be included in a single journal issue today. Instead, this new special issue presents a selection of papers that represent different aspects of current LCA research.

A couple of methodological problems remain unsolved despite more than a decade of research. One of the classical methodological problems in LCA is the problem of allocation. Allocation can be defined as the partitioning of environmental burdens and other material and energy flows to and from a technological activity between the products for which the activity is used. Allocation generally becomes a methodological problem when a technological activity provides different functions for different products. The problem is to decide what share of the environmental burdens of the activity should be allocated to the product being investigated. A large number of solutions have been 
suggested and applied to the allocation problems. An international workshop was dedicated to this problem more than 10 years ago [21]. In the current special issue, the allocation problem at waste solvent incineration is addressed by Seyler et al. This allocation problem occurs because measurements of the consumption of ancillaries and energy carriers, and of emission of pollutants and generation of co-products, always refer to the mixture of waste solvents. To solve this problem Seyler et al. developed a multi-input allocation model of the incineration process. A comprehensive case study on a waste solvent incineration plant from chemical industry provided the necessary data. The results from the multi-input allocation modelling are consumption and emission factors which facilitate the calculation of solvent-specific life cycle inventory results.

It was established at an early stage that the appropriate choices of allocation methods, system boundaries etc. depend on the purpose of the LCA [16]. Several attempts have been made to structure the various applications of LCA and to describe the connection between the study goal and the methodological choices that should be made in the LCA. A distinction between attributional and consequential LCA [22] has become widespread in recent years. Attributional methodology for life cycle inventory analysis (LCI) aims at describing the environmentally relevant physical flows to and from a life cycle and its subsystems. It ideally includes average data on the unit processes. The attributional LCI model does not include unit processes outside the life cycle investigated. Consequential LCI methodology, in contrast, aims at describing how the environmentally relevant physical flows to and from the technosphere will change in response to possible changes in the life cycle. A consequential LCI model includes unit processes that are significantly affected whether they are inside or outside the life cycle. It ideally includes marginal data on bulk production processes in the background system. This distinction is discussed, in this journal, in a paper by Ekvall et al., although they use the terminology retrospective/prospective to denote the two types of LCA. Ekvall et al. analyse the links between the choice of methodology and different theories of normative moral philosophy. They relate the two types of LCA to different theories on the characteristics of a good action, and discuss the pros and cons of each type of LCA and each of the moral theories. The choice of electricity data in an LCA of a conference site with local hydropower production is used as an illustration in the discussion.

Another classical methodological problem in LCA concerns how and how far the results can be aggregated. A radical aggregation requires that different environmental impacts be compared to each other and weighted against each other. There are also decision situations where environmental impacts need to be compared with other costs or benefits that by their nature are expressed in terms of money. Supporting these decisions may require the expression of environmental impacts in monetary units. Using the example of health impacts from road noise, Hofstetter and Müller-Wenk apply five different monetization approaches and quantify the monetary values of one year of sleep disturbance and of interference with communication. They also discuss the monetization of health impacts measured in disability adjusted life years (DALYs), using the example of health impacts due to 1000 truck kilometres. Hofstetter and Müller-Wenk conclude that available monetization methods need careful adaptation for their use to monetize environmental health impacts, that the DALY accounting system may support the systematic monetization and the selection of relevant health endpoints, and that it may well be justified for LCA purposes to perform some novel primary willingness-to-pay studies.

In an LCI model, each factory in the life cycle is often represented by a black box with physical inputs and outputs. Such a simplified model can restrict the validity of LCA as a tool to support decisions on product and process development options and strategic planning. Gäbel and Tillman present a more advanced, flexible model of cement manufacturing. This model predicts the environmental, product and economic performance in a life cycle perspective, simulating different operational alternatives. Gäbel and Tillman use the model to explore selected future operational alternatives, such as an increase in the use of industrial by-products and wastes as raw materials and fuels. They discuss the consequences from a life cycle perspective. The nine simulations show that the use of recovered material and alternative fuel can be increased while maintaining the current requirements on clinker performance. An increase in the use of recovered material and alternative fuel replace the use of resources. The simulations also show that the emissions of $\mathrm{CO}_{2}, \mathrm{NO}_{x}, \mathrm{SO}_{2}, \mathrm{CO}, \mathrm{VOC}, \mathrm{CH}_{4}$ and dust can be reduced by $30-80 \%$ depending on the use of recovered material and alternative fuel.

The research on LCA methodology focuses not only on finding and structuring the most valid methods, but also on developing cost-efficient methods. The data collection in an LCI often requires large resources. To simplify data collection, Rydh and Sun present environmental default data for 17 different material groups. These data sets are based on an evaluation of environmental data from cradle to gate for 214 material cases used in mechanical design. The 17 material groups are defined based on the environmental and physical properties structured into groups. The environmental characteristics for each material group were expressed in terms of LCI data as well as characterised and weighted inventory data. LCI data categories contributing significantly to environmental impact were identified. Multivariate analysis showed weak correlation between material properties and environmental impact. The 
environmental data presented provide averages of LCI data for each material group and can be used as estimates when LCI data for specific materials are missing and/or at early stages of product development.

Andræ et al. present a model for the data collection in LCIs of electronic products. In this model the components are first divided into main groups and then into sub-groups. This division results in process modules for unit processes, some of which are similar for the different components. This makes it possible to reduce the computational effort. Compared to earlier efforts in LCA of electronic products, this model enables more disaggregated results, with respect to both components and processes. The model is demonstrated for a "cradleto-gate" calculation focusing on greenhouse gas emissions. Andræ et al. conclude that intermediate unit processes are important for the total global warming potential of the life cycle.

Current LCA research also includes a large number of case studies. Relating to the electronics sector, Socolof et al. present a comparative LCA of cathode ray tube (CRT) and liquid crystal display (LCD) computer monitors. This case study includes 20 environmental impact categories and can also assist the industry in improving the environmental aspects of each of the monitors. Considering the entire life cycle of each monitor, water eutrophication and aquatic ecotoxicity impacts for the baseline analysis were greater for the LCD while all other impact categories (e.g., resource use, energy, ozone depletion, landfill space use, human health toxicity) were greater for the CRT. The model of energy supply was uncertain and important for the results. Modifying the glass energy data resulted in nine of the 20 impact categories having greater relative life cycle impacts for the LCD than the CRT.

Battisti and Corrado report on an LCA of a solar thermal collector with integrated water storage. The study aims at drawing a thorough environmental profile of the collector, highlighting the most relevant contributions to the total impacts, measured by means of a set of aggregate environmental indicators. In order to evaluate the possible improvements of the system configuration, several sensitivity analyses were performed for different phases of its life cycle. According to this improvement analysis, the reduction of the impacts could be up to $40 \%$. Battisti and Corrado also calculated environmental pay back times. Their values range from 5 to 19 months. This is much lower than the expected lifespan of the systems, which is $15-20$ years.

Results from LCA research are, of course, not just presented in scientific journals. Several international conferences on LCA, or with a significant LCA content, are held at a regular basis. The annual meetings of the European and North American branch of SETAC include several sessions on LCA methodology. In addition, SETAC-Europe organises an annual case study symposium. The Ecobalance conferences in Tsukuba, Japan focus on LCA and are held every other year. A newer series of conferences on life cycle management focus on the more practical aspects of LCA and life cycle thinking. Just to mention a few important examples. This special issue includes a section with papers presented at the Fall 2003 InLCA/LCM conference in Seattle. These papers range from traditional applications of LCA, to new innovative approaches to analyzing the life cycle impacts of products, systems and even industries. Also included in this section are papers which announce the Ecoinvent database and the EPA LCAccess website.

In this section, Tahara et al. present an innovative method for analyzing the eco-efficiency of a company with focus on $\mathrm{CO}_{2}$ generation. "Total $\mathrm{CO}_{2}$ efficiency", "Direct $\mathrm{CO}_{2}$ efficiency" and "Indirect $\mathrm{CO}_{2}$ efficiency" are defined using Input-Output $(\mathrm{I}-\mathrm{O})$ analysis in order to evaluate companies and industry sectors in Japan. The authors found that the method is useful for companies which belong to few industrial sectors, such as beer and petroleum companies. However, it was found that the method was not easy to apply to companies that belong to many industrial sectors. To address this problem, the authors propose a new method called "Integrated $\mathrm{CO}_{2}$ Efficiency Index for Company Evaluation (ICEICE)".

The conference section also includes two traditional comparative LCA studies that exemplify the original intent of the method. First, Hammerschlag et al. detail the results of a comparative LCA evaluating the environmental impacts of four alternative transportation scenarios, with special focus on land use impacts. The scenarios include three fuel cell technologies and one battery electric technology. Each scenario is evaluated for its energy efficiency and land use performance.

da Silva et al. also describe a traditional comparative LCA, in this case comparing Fused Magnesium Phosphate (FMP) and Triple Superphosphate (TSP) fertilizers in the Brazilian context. In their analysis, the authors perform LCIA using the most recent CML 2002 impact categories, including: Global Warming Potential, Ozone Depletion Potential, Human Toxicity Potential, Fresh Water Aquatic Ecotoxicity Potential, Acidification Potential and Eutrophication Potential. The authors found that for the FMP fertilizer, electricity dependence is the main contributor to potential environmental impact. For TSP, the authors find that the significant distances between the phosphate rock mines and manufacturing centers are the main contributors to potential environmental impact.

Rebitzer et al. explore the use of LCA within the context of the Life Cycle Management program at Alcan. The company uses simplified LCAs to evaluate new technologies to aid in decision-making within the company and to ensure that the environmental performance of the company's products is improving. The authors describe the process using an automotive case 
study to demonstrate how LCAs are performed and utilized. This article explores how LCA can be simplified for use internally within companies to make business decisions without compromising the integrity of the results.

In the area of access to data there are two major announcements in the papers of this issue. Frischknecht et al. present the Ecoinvent database developed by the Swiss Centre for Life Cycle Inventories, released in Fall 2003. The database contains over 2500 background processes, with focus primarily on the Swiss and European contexts. The authors describe the quality guidelines, developed at the start of the project to ensure data were acquired in a consistent and transparent manner. This included guidelines for nomenclature and reporting of pollutants. The authors also describe the data exchange format that can be used to integrate the data contained in the database into other databases and softwares. The data format is based on the ISO/TS 14048 data documentation format. In order to calculate LCA results, the database uses matrix inversion with algorithms to help address LCA matrices that are sparse.

Curran and Skone describe LCAccess, an EPAsponsored website intended to promote the use of Life Cycle Assessment (LCA) in business decision-making by facilitating access to data sources that are useful in developing a life cycle inventory (LCI). While the website does not contain data, it provides a global database of potential data sources that can be searched by users to help obtain data for studies.

\section{References}

[1] Hunt RG, Franklin WE. LCA - how it came about - personal reflections on the origin and the development of LCA in the USA. Int J LCA 1996;1(1):4-7.

[2] Problems with life-cycle analysis highlighted by conflict over nappies [ENDS Report, No. 198]. London, UK: Environmental Data Services, Ltd.; 1991. p. 24-6.

[3] Baumann H. Decision making and life cycle assessment. Licentiate thesis. Gothenburg, Sweden: Chalmers University of Technology; 1995.

[4] Ekvall T. Key methodological issues for life cycle inventory analysis of paper recycling. J Clean Prod 1999;7(4):281-94.

[5] Vigon BW, Tolle DA, Cornaby BW, Latham HC, Harrison CL, Boguski TL, et al. Life-cycle assessment: inventory guidelines and principles. Cincinnati, Ohio, USA: U.S. Environmental Protection Agency; 1993.

[6] Lindfors L-G, Christiansen K, Hoffman L, Virtanen Y, Juntilla V, Hanssen O-J, et al. Nordic guidelines on life-cycle assessment [Nord 1995:20]. Stockholm, Sweden: CE Fritzes AB; 1995.

[7] Harmonization of the approaches for life cycle inventories of corrugated board products - FEFCO - document I: methodological guidelines. Paris, France: Ecobilan; 1993.

[8] Strömberg L, Haglind I, Jacobson B, Ekvall T, Eriksson E, Kärnä A, et al. Guidelines on life cycle inventory analysis of pulp and paper [Nordpap DP2/30]. Oslo, Norway: Nordic Industrial Fund; 1997.

[9] Ekvall T, Rydberg T, Hedenberg Ö, Backlund Jacobson B, Pajula T, Wessman H. Guidelines on life cycle impact assessment of pulp and paper [Nordpap DP2/55]. Oslo, Norway: Nordic Industrial Fund; 1997.

[10] Ryding S-O, Ekvall T, Karlsson L, Karlsson R, Nevén C-O, Tillman A-M, et al. Miljöanpassad produktutveckling. Stockholm, Sweden: Industrilitteratur; 1995 [in Swedish].

[11] Wenzel H, Hauschild M, Alting L. Methodology, tools and case studies in product development. Environmental assessment of products, vol. 1. London, UK: Chapman \& Hall; 1997.

[12] Hauschild M, Wenzel H. Scientific background. Environmental assessment of products, vol. 2. London, UK: Chapman \& Hall; 1998.

[13] Heijungs R, Guinée JB, Huppes G, Lankreijer RM, Udo de Haes HA, Wegener Sleeswijk A, et al. Environmental life cycle assessment of products - guide. Leiden, The Netherlands: Centre of Environmental Science; 1992.

[14] Heijungs R, Guinée JB, Huppes G, Lankreijer RM, Udo de Haes HA, Wegener Sleeswijk A, et al. Environmental life cycle assessment of products - backgrounds. Leiden, The Netherlands: Centre of Environmental Science; 1992.

[15] Fava JA, Denison R, Jones B, Curran MA, Vigon B, Selke S, et al, editors. A technical framework for life-cycle assessment. Washington, DC, USA: Society of Environmental Toxicology and Chemistry; 1991.

[16] Consoli F, Allen D, Boustead I, Fava J, Franklin W, Jensen AA, et al, editors. Guidelines for life-cycle assessment: a 'Code of Practice'. 1st ed. Pensacola, Florida, USA: Society of Environmental Toxicology and Chemistry (SETAC); 1993.

[17] Environmental management - life cycle assessment - principles and framework [ISO 14040:1997]. Geneva, Switzerland: International Organization for Standardization; 1997.

[18] Environmental management - life cycle assessment - goal and scope definition and inventory analysis [ISO 14041:1998]. Geneva, Switzerland: International Organization for Standardization; 1998.

[19] Environmental management - life cycle assessment - life cycle impact assessment [ISO 14042:2000]. Geneva, Switzerland: International Organization for Standardization; 2000.

[20] Environmental management - life cycle assessment - life cycle interpretation [ISO 14042:2000]. Geneva, Switzerland: International Organization for Standardization; 2000.

[21] Huppes G, Schneider F, editors. Proceedings of the European Workshop on Allocation in LCA, Leiden, The Netherlands, 2425 February 1994. Brussels, Belgium: SETAC; 1994.

[22] Curran MA, Mann M, Norris G. The international workshop on electricity data for life cycle inventories. J Clean Prod 2005;13(8): 853-62.

A. Russell
Rio Tinto Borax, 26877 Tourney Road,
Valencia, CA 91355-1847, USA
mail address: andrea.russell@ borax.com

T. Ekvall*

Division of Energy Technology, Chalmers University of Technology, SE-41296 Göteborg, Sweden E-mail address: tomas.ekvall@me.chalmers.se

H. Baumann Division of Environmental Systems Analysis, Chalmers University of Technology, SE-41296 Göteborg, Sweden E-mail address: henrikke.baumann@esa.chalmers.se

*Corresponding author. 